\title{
Five-year changes in adiposity and cardio-metabolic risk factors among Guatemalan young adults
}

\author{
Cria O Gregory ${ }^{1}$, Reynaldo Martorell ${ }^{1,2}, \mathrm{KM}^{1,2}$ Venkat Narayan ${ }^{1,2}$, \\ Manuel Ramirez-Zea ${ }^{3}$ and Aryeh D Stein ${ }^{1,2, *}$ \\ ${ }^{1}$ Nutrition and Health Sciences Program, Graduate Division of Biological and Biomedical Sciences, \\ Emory University, Atlanta, GA, USA: ${ }^{2}$ Hubert Department of Global Health, Rollins School of Public Health, \\ Emory University, 1518 Clifton Road, NE, Atlanta, GA 30322, USA: ${ }^{3}$ Institute of Nutrition of Central American \\ and Panama (INCAP), Guatemala City, Guatemala
}

Submitted 12 February 2008: Accepted 8 July 2008: First published online 15 August 2008

\begin{abstract}
Background: Rapidly transitioning societies are experiencing dramatic increases in obesity and cardio-metabolic risk; however, few prospective studies from developing countries have quantified these increases or described their joint relationships.

Methods: We collected dietary, physical activity, demographic, anthropometric and cardio-metabolic risk factor data from 376 Guatemalan young adults in 1997-98 (aged 20-29 years) and in 2002-04 (aged 25-34 years).

Results: In total, $42 \%$ of men and $56 \%$ of women experienced weight gain $>5 \mathrm{~kg}$ in 5 years. Percent body fat (\%BF) and waist circumference (WC) increased by $4.2 \%$ points and $5.5 \mathrm{~cm}$ among men, and $3.2 \%$ points and $3.4 \mathrm{~cm}$ among women, respectively. Five-year increases in both \%BF and WC were associated with lower physical activity, urban residence and shorter height among men but not among women (test for heterogeneity $P<0.05$ for residence and physical activity). Changes in \% $\mathrm{BF}$ and $\mathrm{WC}$ and concomitant changes in cardio-metabolic risk factors were similar for men and women. In standardised regression, change in \%BF was associated with changes in TAG $(\beta=0 \cdot 19 ; 95 \%$ CI $0 \cdot 08,0 \cdot 30)$, total:HDL cholesterol $(\beta=0 \cdot 22 ; 95 \%$ CI $0 \cdot 12,0 \cdot 33)$ and systolic $(\beta=0 \cdot 22 ; 95 \%$ CI $0 \cdot 12,0 \cdot 33)$ and diastolic $(\beta=0 \cdot 18 ; 95 \% \mathrm{CI} 0 \cdot 08,0 \cdot 28)$ blood pressure, but not with glucose; associations were similar for WC.

Conclusions: Over 5 years this relatively young population of Guatemalan adults experienced rapid increases in multiple measures of adiposity, which were associated with adverse changes in lipid and blood pressure levels.
\end{abstract}

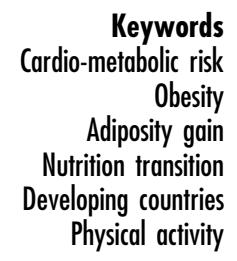

The prevalence of overweight $\left(\mathrm{BMI} \geq 25 \mathrm{~kg} / \mathrm{m}^{2}\right)$ and obesity (BMI $\geq 30 \mathrm{~kg} / \mathrm{m}^{2}$ ) is increasing rapidly in both developed and developing countries, affecting men, women and children ${ }^{(1,2)}$. In 2005 approximately 1.6 billion adults worldwide were overweight and at least 400 million were obese; these estimates are projected to increase to 2.5 billion and more than 700 million, respectively, by $2015^{(3)}$. Much of this increase is attributed to rapid socio-cultural changes occurring in developing countries as the result of globalisation, economic development and urbanisation ${ }^{(4)}$. Many developing countries are currently in various stages of the nutrition transition, characterised by greater access to energy-dense processed foods, increased consumption of meals away from home, shifts in labour structure and transportation systems towards activities that require lower levels of energy expenditure, and reduced physical activity for recreation ${ }^{(5,6)}$. Together these factors create an environment that facilitates positive energy balance and the development of obesity. Longitudinal data from developing countries are limited. However, studies from Iran, Mauritius and China have shown substantial increases in the prevalence of overweight and obesity over 3-8 years ${ }^{(7-9)}$. Additionally, repeat cross-sectional analyses suggest that much of Latin America is experiencing increasing obesity prevalence ${ }^{(10,11)}$.

CVD is now the leading cause of death in all regions of the world with the exception of sub-Saharan Africa, and more than $80 \%$ of the disease burden occurs in low- and middle-income countries ${ }^{(12,13)}$. The global prevalence of diabetes is also increasing rapidly ${ }^{(14)}$, and will further increase the burden of CVD. The projected increases in chronic diseases may be economically devastating for many developing countries, resulting from the loss of 
members of the primary workforce to disability, as well as the substantial cost of long-term disease management ${ }^{(15,16)}$. Obesity is associated with multiple cardio-metabolic risk factors, including atherogenic dyslipidaemia (elevated/ TAG, small dense LDL and low HDL concentrations), elevated blood pressure, and glucose intolerance and insulin resistance ${ }^{(17)}$. Thus, the considerable increase in the global prevalence of overweight and obesity is likely a significant driver of the cardio-metabolic (CVD, diabetes) epidemic. However, the relationship between adiposity and change in cardio-metabolic risk factors has not been well studied in populations experiencing rapid economic development and social change. Some ethnic groups appear to be more susceptible to obesity-related metabolic disturbances ${ }^{(18)}$. Additionally, early life malnutrition paired with later dietary excess may contribute to increased abdominal adiposity, as well as to increased CVD risk independent of adiposity ${ }^{(19)}$. These relationships need to be further explored in different ethnic populations at various stages of the epidemiological and nutrition transitions.

Guatemala, a country in the earlier stages of the nutrition transition, continues to face considerable under-nutrition and communicable disease ${ }^{(20,21)}$, while simultaneously experiencing shifts towards more sedentary lifestyles, higher intakes of dietary fat and sugar, and increases in overweight/obesity and nutrition-related chronic diseases $^{(22,23)}$. In 2000 , the prevalence of overweight was $49 \%$ among women and $34 \%$ among men ${ }^{(20)}$; other cardio-metabolic risk factors have not been studied at the national level. We therefore proceeded to (i) quantify 5-year changes in adiposity and cardio-metabolic risk factors in a population of young adult Guatemalans; (ii) determine the baseline lifestyle and sociodemographic characteristics associated with changes in percent body fat (\%BF) and waist circumference (WC); and (iii) assess the relationship between change in $\% \mathrm{BF}$ and $\mathrm{WC}$ and change in lipids, blood pressure and glucose levels.

\section{Methods}

The Institute of Nutrition of Central American and Panama (INCAP) Longitudinal Study was a nutritional supplementation trial conducted in four rural Guatemalan villages from 1969 to $1977^{(24)}$. The study targeted women and children, and was designed to assess the impact of improved nutrition on child growth and development. Several rounds of follow-up have targeted the former participants of the original study. Our sample included men and women who completed a CVD risk assessment in 1997-98 and again in 2002-04. The target population for the 1997-98 follow-up was the younger half of the original study cohort (aged 20-29 years at follow-up; $n$ 762), while the target population for the 2002-04 follow-up included all child participants in the original study (aged 25-42 years at follow-up; $n$ 2392). Details on tracking and attrition from both studies have been published previously ${ }^{(25,26)}$. Of the 473 participants examined in 1997-98, seventeen were living out of the country, thirteen could not be located and seven refused, and thus were not re-examined in the 2002-04 follow-up. Additionally, twenty-four participants of the 1997-98 study were examined in 2002-04 but excluded due to current pregnancy or non-fasting status, and another thirty-eight completed some of the interviews but not the physical measures required for this analysis. All data collection was approved by the human subjects review boards at INCAP and Emory University, and written informed consent was obtained from all participants.

\section{Lifestyle factors}

All questionnaires were interviewer-administered. Dietary intake was assessed with a fifty-two item FFQ developed for this population ${ }^{(27)}$. Nutrient intakes were estimated using the INCAP nutrient database ${ }^{(28)}$, which is based on foods commonly consumed in Guatemala, and supplemented with data from the US Department of Agriculture Nutrient Database ${ }^{(29)}$. A physical activity questionnaire was used to ascertain all activities performed on a typical work day, over the preceding year, including time spent sleeping, mode of transportation, type of occupation, chores and leisure time. Activities were converted to metabolic equivalents (MET) ${ }^{(30)}$ and used to calculate a $24 \mathrm{~h}$ physical activity level ${ }^{(31)}$. Participants were asked to identify themselves as current, previous or never smokers; we combined previous and never smokers, creating a dichotomous variable for current smoking status (yes/no).

\section{Sociodemographic factors}

We defined residence as rural when residing in one of the four original study villages, and urban when residing in Guatemala City. A socio-economic status (SES) index from 1996 census data was constructed using principal components factor analysis on variables regarding household structure (e.g. number of rooms, types of walls, electricity) and durable goods (e.g. radio, television, refrigerator, car) ${ }^{(32)}$. Data on parity were not collected in 1997-98; however, an extensive reproductive history was collected in 2002-04. Using the dates of each child's birth we were able to calculate the number of live births by each woman.

\section{Antbropometry}

Anthropometric measures were obtained in duplicate by trained field researchers; if the measures differed by greater than $0.5 \mathrm{~kg}$ for body weight, $1.0 \mathrm{~cm}$ for height or $1.5 \mathrm{~cm}$ for $\mathrm{WC}$, a third measure was taken and the closest two were used. We calculated \%BF using predictive equations developed for this population ${ }^{(33)}$. We defined overweight as $\mathrm{BMI} \geq 25 \mathrm{~kg} / \mathrm{m}^{2}$ and obesity as $\mathrm{BMI} \geq$ $30 \mathrm{~kg} / \mathrm{m}^{2}$ and abdominal obesity as WC $>102 \mathrm{~cm}$ among men and $>88 \mathrm{~cm}$ among women ${ }^{(34)}$. 


\section{Plasma lipids and glucose}

All participants were fasting $>8 \mathrm{~h}$; finger prick blood samples were analysed with an enzymatic peroxidase dry chemistry method (Cholestech LDX System, Hayward, CA, USA) to determine lipid and glucose concentrations. We defined adverse lipid measures as total cholesterol $\geq 5.2 \mathrm{mmol} / \mathrm{l}(\geq 200 \mathrm{mg} / \mathrm{dl}), \mathrm{HDL}$ cholesterol $<1 \cdot 0 \mathrm{mmol} / \mathrm{l}$ $(<40 \mathrm{mg} / \mathrm{dl})$ among men and $<1.3 \mathrm{mmol} / \mathrm{l}(<50 \mathrm{mg} / \mathrm{dl})$ among women, total:HDL cholesterol ratio $\geq 5 \cdot 0$ and TAG $\geq 1.7 \mathrm{mmol} / 1$ ( $\geq 150 \mathrm{mg} / \mathrm{dl})^{(35)}$. We defined impaired fasting glucose as glucose $\geq 5.6 \mathrm{mmol} / 1$ ( $\geq 100 \mathrm{mg} / \mathrm{dl})$ and diabetes as glucose $\geq 7 \cdot 0 \mathrm{mmol} / 1(\geq 126 \mathrm{mg} / \mathrm{dl})^{(36)}$.

\section{Blood pressure}

Measurements were taken at least 3 min apart with a digital sphygmomanometer (A\&D model UA-767; A\&D Medical, Milpitas, CA, USA) on the left arm resting on a table at the heart level. Three cuff sizes were available and selected for use based on arm circumference. If blood pressure measurements differed by more than $10 \mathrm{mmHg}$, a fourth was taken; otherwise the two closest measures were averaged. We defined hypertension as systolic $\geq 130$ and/or diastolic blood pressure $\geq 85 \mathrm{mmHg}^{(38)}$.

\section{Statistical analysis}

We analysed the distribution of all variables, calculated 5-year changes by subtracting 1997-98 values from those obtained in 2002-04, and estimated the mean change and its associated 95\% CI. We used multiple linear regression to model the associations of key baseline lifestyle (smoking status (men only), dietary energy intake, dietary fat intake, physical activity level) and sociodemographic (age, parity (women only), socio-economic status, rural/ urban residence) variables with changes in \%BF and WC as continuous variables. Due to previous analyses suggesting determinants of weight or adiposity gain differ by sex ${ }^{(7,39)}$, and the inclusion of parity and smoking only in models for women or men, respectively, we stratified these analyses by sex. We used multiple linear regression models to estimate the association of changes in $\% \mathrm{BF}$ and WC (each considered separately) on changes in TAG, total:HDL cholesterol ratio, systolic and diastolic blood pressures, and glucose. These models were adjusted for the corresponding baseline anthropometric and cardiometabolic risk factor measures, age, smoking status and supplementation group in the original study; dietary energy and fat and physical activity level were considered, but their inclusion did not affect any of the estimates, and we excluded them for parsimony. Estimates for men and women were not heterogeneous; thus, we pooled the samples and re-ran the analyses in order to increase precision. We defined the presence of the metabolic syndrome using American Heart Association criteria( ${ }^{(37)}$ and used logistic regression to assess the association of change in $\% \mathrm{BF}$ and in WC with incident metabolic syndrome. We used multiple imputation methods to impute all missing covariates $^{(40,41)}$; this included socio-economic status for sixteen persons, parity for thirty-four women, and \%BF and WC for twenty persons (only in models where \%BF and WC were covariates, not dependent variables). All analyses were conducted with both original and imputed datasets in order to assess any difference in results. All statistical analyses were performed using SAS statistical software package version $9 \cdot 1 \cdot 3$ (SAS Institute, Cary, NC, USA).

\section{Results}

In the 1997-98 study, participants were aged 20-29 years, with $76 \%$ living in rural villages (Table 1 ). The average diet provided $20 \%$ of energy from fat and $68 \%$ of energy from carbohydrates; $56 \%$ of men, but only $2 \%$ of women, reported a level of physical activity above that $(\geq 1 \cdot 7 \mathrm{MET} / \mathrm{d})$ recommended to prevent obesity ${ }^{(42)}$.

Table 1 Characteristics of a sample of Guatemalan men and women surveyed in 1997-98*

\begin{tabular}{|c|c|c|c|c|}
\hline & \multicolumn{2}{|c|}{ Men $(n 181)$} & \multicolumn{2}{|c|}{ Women ( $n$ 195) } \\
\hline & Mean & SD & Mean & SD \\
\hline Age (years) & $24 \cdot 5$ & $2 \cdot 4$ & $24 \cdot 4$ & $2 \cdot 2$ \\
\hline Height $(\mathrm{cm})$ & $163 \cdot 1$ & $6 \cdot 5$ & $151 \cdot 1$ & $5 \cdot 2$ \\
\hline $\begin{array}{l}\text { Physical activity (MET/d) } \\
\geq 1.7 \mathrm{MET} / \mathrm{d}(\%)\end{array}$ & \multicolumn{2}{|c|}{$56 \cdot 2$} & \multicolumn{2}{|c|}{$2 \cdot 1$} \\
\hline Dietary energy $(\mathrm{kcal} / \mathrm{kg})$ & 3634.5 & $1308 \cdot 6$ & $2518 \cdot 7$ & $689 \cdot 2$ \\
\hline Dietary fat ( $\%$ of energy) & $19 \cdot 7$ & $4 \cdot 6$ & $20 \cdot 4$ & $4 \cdot 5$ \\
\hline Dietary carbohydrate ( $\%$ of energy) & $68 \cdot 4$ & $5 \cdot 7$ & $67 \cdot 5$ & $5 \cdot 3$ \\
\hline Socio-economic status & 0.4 & $2 \cdot 0$ & $-0 \cdot 1$ & 1.9 \\
\hline Rural residence (\%) & \multicolumn{2}{|c|}{$\begin{array}{l}70 \cdot 2 \\
41 \cdot 4\end{array}$} & \multicolumn{2}{|c|}{$\begin{array}{c}82.6 \\
0.5\end{array}$} \\
\hline Current smoker (\%) & & & \multicolumn{2}{|c|}{0.5} \\
\hline Parity & \multicolumn{2}{|c|}{$\mathrm{N} / \mathrm{A}$} & $1 \cdot 2$ & $1 \cdot 1$ \\
\hline 0 children $(\%)$ & \multicolumn{2}{|c|}{$\mathrm{N} / \mathrm{A}$} & \multicolumn{2}{|c|}{$30 \cdot 5$} \\
\hline $1-2$ children $(\%)$ & \multicolumn{2}{|c|}{$\mathrm{N} / \mathrm{A}$} & \multicolumn{2}{|c|}{$50 \cdot 3$} \\
\hline 3-5 children (\%) & \multicolumn{2}{|c|}{ N/A } & \multicolumn{2}{|c|}{$19 \cdot 2$} \\
\hline
\end{tabular}

MET, metabolic equivalents; N/A, not applicable.

*Values are mean and SD or prevalence. 
Approximately one-third of women had not given birth, and half had given birth once or twice. The majority of participants gained weight over the 5-year interval, with $42 \%$ of men and $56 \%$ of women experiencing weight gain $>5 \mathrm{~kg}$ (Table 2). Although subjects were as young as 20 years in 1997, there were no changes in height over 5 years and linear growth can be excluded as a cause of changes in body composition. Among persons who experienced $>5 \mathrm{~kg}$ weight gain, mean changes in $\% \mathrm{BF}$ and WC were $7 \cdot 6 \%$ points and $10 \cdot 2 \mathrm{~cm}$ among men and $5.9 \%$ points and $7 \cdot 7 \mathrm{~cm}$ among women, respectively.

The prevalence of $\mathrm{BMI}<18.5 \mathrm{~kg} / \mathrm{m}^{2}$ was very low in this population, and decreased further over the 5 -year period, whereas the prevalence of obesity increased by $4 \cdot 3 \%$ points among men and by $12 \cdot 6 \%$ points among women (Table 3 ). Mean $\%$ BF increased by $4 \cdot 2 \%$ points among men and by $3 \cdot 2 \%$ points among women, and WC increased by 5.5 and $3.4 \mathrm{~cm}$, respectively. TAG, total cholesterol, HDL cholesterol, glucose and prevalence of the metabolic syndrome all increased among both men and women, while the total:HDL cholesterol ratio increased in men only. Systolic and diastolic blood pressure increased in women but decreased in men.

Among men, baseline shorter height, lower levels of physical activity and urban residence were associated with increases in \%BF (Table 4). No relationships among sociodemographic and lifestyle variables and changes in $\% \mathrm{BF}$ were found among women. With WC as the dependent variable, results were consistent among both men and women. Upon finding no baseline factors associated with changes in \%BF or WC among women, we examined parity over the 5-year period; $14 \%$ of women had no children,

Table 2 Distribution of 5-year weight change categories, and mean $(95 \% \mathrm{Cl})$ change in \%BF and WC associated with these weight change categories, among a sample of men and women in Guatemala

\begin{tabular}{|c|c|c|c|c|c|c|c|c|c|c|}
\hline \multirow[b]{3}{*}{ 5-year change in weight } & \multicolumn{5}{|c|}{ Men (n 165) } & \multicolumn{5}{|c|}{ Women $(n$ 175) } \\
\hline & \multicolumn{3}{|c|}{ Change \%BF } & \multicolumn{2}{|c|}{ Change WC (cm) } & \multicolumn{3}{|c|}{ Change \%BF } & \multicolumn{2}{|c|}{ Change WC (cm) } \\
\hline & $\%$ & Mean & $95 \% \mathrm{Cl}$ & Mean & $95 \% \mathrm{Cl}$ & $\%$ & Mean & $95 \% \mathrm{Cl}$ & Mean & $95 \% \mathrm{Cl}$ \\
\hline Loss $(<-2 \mathrm{~kg})$ & $4 \cdot 9$ & $-1 \cdot 1$ & $-2 \cdot 6,0 \cdot 5$ & $-2 \cdot 0$ & $-3 \cdot 9,-0.2$ & $8 \cdot 0$ & $-3 \cdot 2$ & $-4 \cdot 3,-2 \cdot 2$ & $-6 \cdot 8$ & $-9 \cdot 5,-4 \cdot 1$ \\
\hline Maintain $(-2$ to $2 \mathrm{~kg})$ & $28 \cdot 5$ & $0 \cdot 7$ & $-0.2,1 \cdot 5$ & 0.7 & $0 \cdot 1,1 \cdot 6$ & $18 \cdot 9$ & -0.7 & $-1 \cdot 2,-0 \cdot 2$ & $-3 \cdot 0$ & $-1 \cdot 8,1 \cdot 4$ \\
\hline Modest gain $(>2$ to $5 \mathrm{~kg})$ & $24 \cdot 9$ & 3.6 & $2 \cdot 9,4 \cdot 3$ & $4 \cdot 6$ & $3 \cdot 9,5 \cdot 3$ & $17 \cdot 1$ & $1 \cdot 7$ & $1 \cdot 3,2 \cdot 2$ & 1.5 & $0 \cdot 1,3 \cdot 0$ \\
\hline Large gain $(>5 \mathrm{~kg})$ & $41 \cdot 8$ & $7 \cdot 6$ & $6 \cdot 8,8 \cdot 3$ & $10 \cdot 2$ & $9 \cdot 2,11 \cdot 1$ & $56 \cdot 0$ & $5 \cdot 9$ & $3 \cdot 3,6 \cdot 5$ & $7 \cdot 7$ & $6 \cdot 6,8 \cdot 9$ \\
\hline
\end{tabular}

$\mathrm{BF}$, body fat; WC, waist circumference.

Table 3 Mean and SD or prevalence in 1997-98 and mean (95\% Cl) change over 5 years of anthropometric and cardio-metabolic risk factors among a sample of men and women in Guatemala

\begin{tabular}{|c|c|c|c|c|c|c|c|c|c|c|}
\hline & \multicolumn{5}{|c|}{ Men } & \multicolumn{5}{|c|}{ Women } \\
\hline & \multirow[b]{2}{*}{$n$} & \multicolumn{2}{|c|}{ Baseline } & \multicolumn{2}{|c|}{ Change } & \multirow[b]{2}{*}{$n$} & \multicolumn{2}{|c|}{ Baseline } & \multicolumn{2}{|c|}{ Change } \\
\hline & & Mean & SD & Mean & $95 \% \mathrm{Cl}$ & & Mean & SD & Mean & $95 \% \mathrm{Cl}$ \\
\hline Weight (kg) & 165 & $59 \cdot 6$ & $8 \cdot 1$ & $4 \cdot 8$ & $4 \cdot 0,5 \cdot 6$ & 175 & $54 \cdot 8$ & 10.9 & $5 \cdot 9$ & $5 \cdot 0,6 \cdot 7$ \\
\hline BMI $\left(\mathrm{kg} / \mathrm{m}^{2}\right)$ & 165 & $22 \cdot 4$ & $2 \cdot 4$ & $2 \cdot 0$ & $1 \cdot 8,2 \cdot 3$ & 175 & $24 \cdot 0$ & $4 \cdot 1$ & $2 \cdot 8$ & $2 \cdot 5,3 \cdot 2$ \\
\hline$<18.5(\%)$ & 165 & \multicolumn{2}{|c|}{$2 \cdot 4$} & \multicolumn{2}{|c|}{0.6} & 175 & \multicolumn{2}{|c|}{$5 \cdot 1$} & \multicolumn{2}{|c|}{$3 \cdot 4$} \\
\hline$\geq 25(\%)$ & 165 & \multirow{2}{*}{\multicolumn{2}{|c|}{$\begin{array}{r}13 \cdot 9 \\
1 \cdot 8\end{array}$}} & & & 175 & & & & \\
\hline$\geq 30(\%)$ & 165 & & & \multicolumn{2}{|c|}{$4 \cdot 3$} & 175 & \multicolumn{2}{|c|}{$10 \cdot 3$} & \multicolumn{2}{|c|}{$12 \cdot 6$} \\
\hline$\% B F$ & 164 & $14 \cdot 9$ & $4 \cdot 3$ & $4 \cdot 2$ & $3 \cdot 6,4 \cdot 8$ & 171 & $31 \cdot 3$ & $6 \cdot 2$ & $3 \cdot 2$ & $2 \cdot 4,4 \cdot 5$ \\
\hline WC (cm) & 164 & $79 \cdot 5$ & $5 \cdot 8$ & $5 \cdot 5$ & $4 \cdot 7,6 \cdot 0$ & 171 & $87 \cdot 8$ & $9 \cdot 8$ & $3 \cdot 4$ & $2 \cdot 4,4 \cdot 5$ \\
\hline$>102 \mathrm{~cm}(\mathrm{~m}),>88 \mathrm{~cm}(\mathrm{w})(\%)$ & 164 & 0 & & \multicolumn{2}{|c|}{$4 \cdot 3$} & 171 & 38 & & \multicolumn{2}{|c|}{$19 \cdot 3$} \\
\hline $\begin{array}{l}\text { TAG }(\mathrm{mmol} / \mathrm{l}) \\
\geq 1.7 \mathrm{mmol} / \mathrm{l}(\%)\end{array}$ & $\begin{array}{l}120 \\
120\end{array}$ & \multicolumn{2}{|c|}{$25 \cdot 8$} & \multicolumn{2}{|c|}{$19 \cdot 6$} & $\begin{array}{l}152 \\
152\end{array}$ & $\begin{array}{l}1 \cdot 5 \\
30\end{array}$ & $9^{0.8}$ & \multicolumn{2}{|c|}{$16 \cdot 6$} \\
\hline $\begin{array}{l}\text { Total cholesterol }(\mathrm{mmol} / \mathrm{l}) \\
\geq 5.2 \mathrm{mmol} / \mathrm{l}(\%)\end{array}$ & $\begin{array}{l}121 \\
121\end{array}$ & \multicolumn{2}{|c|}{$2 \cdot 5$} & $4 \cdot 1$ & $1^{0 \cdot 3,0 \cdot 5}$ & $\begin{array}{l}163 \\
163\end{array}$ & ${ }^{3 \cdot 8}$ & 0.7 & $0 \cdot 4$ & $1^{0 \cdot 3,0 \cdot 5}$ \\
\hline HDL cholesterol $(\mathrm{mmol} / \mathrm{l})$ & $\begin{array}{l}121 \\
121\end{array}$ & 0.9 & 0.3 & 0.05 & $0.01,0.08$ & $\begin{array}{l}163 \\
163\end{array}$ & $\begin{array}{l}1 \cdot 0 \\
84\end{array}$ & $0 \cdot 3$ & 0.06 & $0.02,0.1$ \\
\hline $\begin{array}{l}\text { Total:HDL cholesterol ratio } \\
\quad \geq 5 \%\end{array}$ & $\begin{array}{l}121 \\
121\end{array}$ & \multicolumn{2}{|c|}{$23 \cdot 1$} & $10 \cdot 8$ & $8^{0 \cdot 1,0 \cdot 6}$ & $\begin{array}{l}163 \\
163\end{array}$ & $\begin{array}{l}4 \cdot 3 \\
19\end{array}$ & $6^{1 \cdot 1}$ & $0 \cdot 1$ & $8^{-0 \cdot 1,0 \cdot 3}$ \\
\hline $\begin{array}{l}\text { Glucose }(\mathrm{mmol} / \mathrm{l}) \\
\geq 5.6 \mathrm{mmol} / \mathrm{l}(\%) \\
\geq 7.0 \mathrm{mmol} / \mathrm{l}(\%)\end{array}$ & $\begin{array}{l}121 \\
121 \\
121\end{array}$ & \multicolumn{2}{|c|}{$\begin{array}{c}10 \cdot 7 \\
0\end{array}$} & \multicolumn{2}{|c|}{$\begin{array}{l}3 \cdot 4 \\
0\end{array}$} & $\begin{array}{l}163 \\
163 \\
163\end{array}$ & \multicolumn{2}{|c|}{$\begin{array}{l}5 \cdot 5 \\
0\end{array}$} & \multicolumn{2}{|c|}{$\begin{array}{l}9 \cdot 2 \\
1 \cdot 8\end{array}$} \\
\hline $\mathrm{SBP}(\mathrm{mmHg})$ & 181 & $120 \cdot 3$ & $10 \cdot 1$ & $-3 \cdot 4$ & $-5 \cdot 0,-1 \cdot 9$ & 195 & $103 \cdot 3$ & $10 \cdot 5$ & $3 \cdot 5$ & $2 \cdot 0,5 \cdot 0$ \\
\hline DBP $(\mathrm{mmHg})$ & 181 & $72 \cdot 9$ & $7 \cdot 7$ & $-1 \cdot 5$ & $-2 \cdot 8,-0 \cdot 01$ & 195 & $64 \cdot 9$ & $7 \cdot 8$ & $3 \cdot 4$ & $2 \cdot 1,4 \cdot 7$ \\
\hline$\geq 130 / 85 \mathrm{mmHg}(\%)$ & 181 & 22 & & & & 195 & & & & 1 \\
\hline Metabolic syndrome (\%) & 120 & 13 & & & & 152 & 20 & & & \\
\hline
\end{tabular}

\%BF, percent body fat; WC, waist circumference; m, men; w, women; SBP, systolic blood pressure; DBP, diastolic blood pressure. 
Table 4 Baseline sociodemographic and lifestyle predictors of 5-year change in \%BF among Guatemalan men and women surveyed in 1997-98 and 2002-04*

\begin{tabular}{|c|c|c|c|c|}
\hline & \multicolumn{4}{|c|}{ Change in \%BF (\%) } \\
\hline & \multicolumn{2}{|c|}{ Men ( $n$ 165) } & \multicolumn{2}{|c|}{ Women ( $n$ 175) } \\
\hline & Estimate & $95 \% \mathrm{Cl}$ & Estimate & $95 \% \mathrm{Cl}$ \\
\hline Age (years) & -0.08 & $-0.23,0.07$ & $-0 \cdot 13$ & $-0.31,0.06$ \\
\hline Baseline \%BF & $0 \cdot 12$ & $-0.04,0.28$ & $-0 \cdot 13$ & $-0.33,0.06$ \\
\hline Height $(\mathrm{cm})$ & $-0 \cdot 19$ & $-0.34,-0.04$ & 0.07 & $-0.12,0.26$ \\
\hline Physical activity level (MET/d) & $-0 \cdot 22$ & $-0.41,-0.03$ & 0.08 & $-0 \cdot 12,0 \cdot 27$ \\
\hline Dietary energy (kcal/kg) & $-0 \cdot 10$ & $-0 \cdot 35,0 \cdot 16$ & 0.06 & $-0 \cdot 16,0.22$ \\
\hline Dietary fat (\% of energy) & -0.07 & $-0.23,0.08$ & -0.03 & $-0.21,0 \cdot 15$ \\
\hline Socio-economic status & 0.06 & $-0 \cdot 13,0.24$ & $-0 \cdot 01$ & $-0 \cdot 20,0 \cdot 19$ \\
\hline Rural residence & $-0 \cdot 41$ & $-0.76,-0.06$ & 0.01 & $-0.46,0.48$ \\
\hline Current smoking status & 0.03 & $-0 \cdot 13,0 \cdot 19$ & $\mathrm{~N} / \mathrm{A}$ & $\mathrm{N} / \mathrm{A}$ \\
\hline Parity $n$ & $\mathrm{~N} / \mathrm{A}$ & $\mathrm{N} / \mathrm{A}$ & 0.01 & $-0 \cdot 16,0 \cdot 19$ \\
\hline
\end{tabular}

\%BF, percent body fat; MET, metabolic equivalents; N/A, not applicable.

${ }^{*}$ Values are standardised regression coefficients and $95 \% \mathrm{Cl}$ from multivariable models; models are adjusted for all other variables in the table (smoking included in models for men only and parity in models for women only) and early life supplementation.

Table 5 Associations between 5-year change in \%BF and change in cardio-metabolic risk factors among Guatemalan adults surveyed in 1997-98 and 2002-04*

\begin{tabular}{lccr}
\hline & $n$ & Estimate per 1\% change in \%BF & \multicolumn{1}{c}{$95 \% \mathrm{Cl}$} \\
\hline Change in TAG (mmol/l) & 272 & $0 \cdot 19$ & $0 \cdot 08,0 \cdot 30$ \\
Change in total:HDL cholesterol ratio & 284 & $0 \cdot 22$ & $0 \cdot 12,0 \cdot 33$ \\
Change in glucose (mmol/l) & 284 & $0 \cdot 02$ & $-0 \cdot 09,0 \cdot 13$ \\
Change in SBP (mmHg) & 376 & $0 \cdot 22$ & $0 \cdot 12,0 \cdot 33$ \\
Change in DBP (mmHg) & 376 & $0 \cdot 18$ & $0.08,0 \cdot 28$
\end{tabular}

\%BF, percent body fat; SBP, systolic diastolic blood pressure; DBP, diastolic blood pressure.

*In separate linear regression models, change in \%BF is the predictor variable and change in each of the cardio-metabolic risk factors is the dependent variable. Values are standardized regression coefficients and $95 \% \mathrm{Cl}$; models are adjusted for baseline age, baseline $\% \mathrm{BF}$, baseline cardio-metabolic risk factor level, sex, smoking status and early life supplementation.

$56 \%$ had one child, $28 \%$ had two children and 2\% had three children. Similar to findings for baseline parity, the number of births experienced by women over the 5-year period was not associated with adiposity gain.

Independent of baseline levels of \%BF or cardiometabolic risk factors, change in \%BF was associated with changes in TAG, total:HDL cholesterol ratio, systolic blood pressure and diastolic blood pressure; no association was found with change in glucose (Table 5). The results were similar in models when change in WC was the predictor variable. Additionally, we controlled for change in BMI in models with change in WC as the predictor variable in order to assess whether there was an effect of increasing abdominal adiposity independent of overall adiposity; in these models, change in WC was no longer significant. The 5 -year incidence of metabolic syndrome was associated with change in $\% \mathrm{BF}(\mathrm{OR}=1 \cdot 19 ; 95 \% \mathrm{CI} 1 \cdot 08,1 \cdot 31$ per unit change in $\% \mathrm{BF})$ and with change in $\mathrm{WC}(\mathrm{OR}=1 \cdot 13 ; 95 \%$ CI $1 \cdot 07,1 \cdot 20$ per $\mathrm{cm}$ change in WC).

\section{Discussion}

The rapid increases in adiposity and associated adverse changes in cardio-metabolic risk factors seen in 5 years in this young adult population are cause for serious concern. Relatively few participants maintained weight, with almost half of men and more than half of women gaining greater than $5 \mathrm{~kg}$. The average weight gain among both men and women was approximately $1 \mathrm{~kg} /$ year; this is greater than the average weight gain observed in developed countries $(0 \cdot 4-0 \cdot 9 \mathrm{~kg} / \text { year })^{(43-45)}$. Weight gain was associated with increases in overall adiposity as well as abdominal adiposity.

We found an annual increase in the prevalence of overweight of $3.9 \%$ among men and $5 \cdot 1 \%$ among women. These rates are considerably higher than the $0 \cdot 3-0 \cdot 9 \%$ annual increases seen across various age, racial/ethnic and socio-economic groups in the $\mathrm{USA}^{(46)}$. These rates of annual increase in overweight prevalence are also substantially higher than those observed in several other countries experiencing the nutrition transition: $1 \%$ per year among Chinese adults 20-45 years ${ }^{(8)} ; 0 \cdot 6 \%$ and $1 \cdot 2 \%$ per year among Brazilian men and women, respectively ${ }^{(47)}$; $2 \cdot 4 \%$ per year among Mexican women ${ }^{(10)}$; and $2.7 \%$ and $2 \cdot 0 \%$ per year among Mauritian men and women, respectively $^{(7)}$. Some of the difference may be due to the young age of our cohort, as several studies have documented more rapid weight gain among younger compared to older adults ${ }^{(43)}$. However, the rates of increase we found 
were still larger than estimates we were able to find among populations of similar age ${ }^{(7,46)}$.

The determinants of change in weight or adiposity are inconsistent among populations experiencing developmental transitions ${ }^{(7,8)}$. We found taller height, rural residence and physical activity to be inversely associated with increased adiposity among men, suggesting that adequate early life nutrition and promotion of physical activity may be primary targets for health promotion. We only examined associations between baseline factors and changes in adiposity; it may be that changes in behaviour or other experiences over the 5-year period also contributed to weight gain. Our lack of findings among women may be due to imprecision in our instruments or lack of true variance, particularly regarding physical activity levels.

Changes in \%BF and WC were associated with change in a variety of cardio-metabolic risk factors. The changes in these anthropometric indicators accounted for approximately $4-11 \%$ of the variance in lipid and blood pressure changes, which is consistent with other studies ${ }^{(48,49)}$. The strength of associations of increased adiposity with increased cardio-metabolic risk factors was similar for \%BF and $\mathrm{WC}$, suggesting that atherogenic changes were probably not attributed to specific increases in visceral adiposity. We were surprised that adiposity gain was not associated with increased fasting glucose given the strong association between obesity and diabetes $^{(50)}$. One explanation may be a lag-time effect, with 5 years being an insufficient time period for increased adiposity to substantially influence glucose levels. Other studies using single measures of fasting glucose have found inconsistent associations between change in adiposity and change in glucose ${ }^{(48,51)}$. Future studies may need to be performed in multi-ethnic cohorts using repeat measures in order to clarify these associations.

Individual behavioural changes, on their own, are unlikely to stem the rapid increases in adiposity occurring in this population ${ }^{(52)}$. Broader action at the community, national and international level is needed. Data from the USA suggest that affecting the energy balance by only $100 \mathrm{kcal} / \mathrm{d}$ may be sufficient to prevent weight gain in most of the population ${ }^{(45)}$, a reduction that could be obtained by just one extra mile of walking or consumption of one less soda. Programmes and policy from several developing countries provide examples on how to realise such changes. Models for promoting physical activity include Ciclovía in Bogota, Colombia, where streets are closed to traffic on Sundays, creating an extensive network of bike paths and other exercise options $^{(53)}$, and Agito São Paulo in the state of São Paulo, Brazil, which is a multi-level intervention that uses 'megaevents' and mass media to promote physical activity ${ }^{(54)}$. Mauritius provides a model for implementing change in dietary fat consumption; government-mandated changes in the composition of common cooking oils reduced saturated fat intake, increased unsaturated fat intake and overall had a beneficial effect on population serum lipid measures ${ }^{(55)}$.

As these instances illustrate, other developing countries have begun to identify potentially modifiable factors that contribute to an obesogenic environment and address these factors through public health programmes. Our findings concerning the rapid increase in weight and $\mathrm{BF}$ in young Guatemalan adults should stimulate the development and implementation of locally appropriate, feasible and effective interventions.

\section{Acknowledgements}

Sources of funding: Funding was provided by the Nestle Foundation, National Institutes of Health (TW005598, HD046125) and American Heart Association (pre-doctoral fellowship to C.O.G.).

Conflict of interest: None of the authors has any conflicts of interest.

Authorship responsibilities: C.O.G. planned and carried out the analyses and drafted the manuscript; all authors provided critical revision of the paper and read and approved the final manuscript.

\section{References}

1. Martorell R, Khan LK, Hughes ML \& Grummer-Strawn LM (1998) Obesity in Latin American women and children. J Nutr 128, 1464-1473.

2. York DA, Rossner S, Caterson I et al. (2004) Prevention Conference VII: Obesity, a worldwide epidemic related to heart disease and stroke: Group I: worldwide demographics of obesity. Circulation 110, e463-e470.

3. World Health Organization (2006) Overweight and Obesity. Fact Sheet no. 311. http://www.who.int/mediacentre/ factsheets/fs311/en/print.html (accessed January 2008).

4. Popkin BM \& Gordon-Larsen P (2004) The nutrition transition: worldwide obesity dynamics and their determinants. Int J Obes Relat Metab Disord 28, Suppl. 3, S2-S9.

5. Drewnowski A \& Popkin BM (1997) The nutrition transition: new trends in the global diet. Nutr Rev $\mathbf{5 5}$, $31-43$.

6. Monda KL, Adair LS, Zhai F \& Popkin BM (2007) Longitudinal relationships between occupational and domestic physical activity patterns and body weight in China. Eur J Clin Nutr (Epublication ahead of print version).

7. Hodge AM, Dowse GK, Gareeboo H, Tuomilehto J, Alberti KG \& Zimmet PZ (1996) Incidence, increasing prevalence, and predictors of change in obesity and fat distribution over 5 years in the rapidly developing population of Mauritius. Int J Obes Relat Metab Disord 20, 137-146.

8. Bell AC, Ge K \& Popkin BM (2001) Weight gain and its predictors in Chinese adults. Int J Obes Relat Metab Disord 25, 1079-1086.

9. Azizi F, Azadbakht L \& Mirmiran P (2005) Trends in overweight, obesity and central fat accumulation among Tehranian adults between 1998-1999 and 2001-2002: Tehran lipid and glucose study. Ann Nutr Metab 49, 3-8.

10. Rivera JA, Barquera S, Gonzalez-Cossio T, Olaiz G \& Sepulveda J (2004) Nutrition transition in Mexico and in other Latin American countries. Nutr Rev 62, Part 2, S149-S157. 
11. Kain J, Vio F \& Albala C (2003) Obesity trends and determinant factors in Latin America. Cad Saude Publica 19, Suppl. 1, S77-S86.

12. Ezzati M, Vander Hoorn S, Lopez AD et al. (2006) Comparative quantification of mortality and burden of disease attributable to selected risk factors. In Global Burden of Disease and Risk Factors, 2nd ed [AD Lopez, CD Mathers, M Ezzati, DT Jamison and CJL Murray, editors]. New York: Oxford University Press and the World Bank.

13. Gaziano TA, Reddy KS, Paccaud F et al. (2006) Cardiovascular disease. In Disease Control Priorities in Developing Countries [DT Jamison, JG Breman, AR Measham et al., editors]. New York: Oxford University Press and World Bank.

14. International Diabetes Federation (2003) Diabetes Atlas. Brussels: International Diabetes Federation.

15. Narayan KMV, Zhang P, Kanaya AM et al. (2006) Diabetes: the pandemic and potential solutions. In Disease Control Priorities in Developing Countries [DT Jamison, JG Breman, AR Measham et al., editors]. New York: Oxford University Press and World Bank.

16. Daar AS, Singer PA, Persad DL et al. (2007) Grand challenges in chronic non-communicable diseases. Nature 450, 494-496.

17. Grundy SM (1998) Multifactorial causation of obesity: implications for prevention. Am J Clin Nutr 67, Suppl., 563S-572S.

18. World Health Organization; International Association for the Study of Obesity; International Obesity Task Force (2000) The Asia-Pacific Perspective: Redefining Obesity and its Treatment. Sydney: WHO.

19. Remale C, Bieswal F \& Reusens B (2004) Programming of obesity and cardiovascular disease. Int J Obes Relat Metab Disord 28, S46-S53.

20. Marini A \& Gragnolati M (2003) Malnutrition and Poverty in Guatemala. Policy Research Working Paper no. 2967. Washington, DC: World Bank.

21. Ministerio de Salud Publica y Asistencia Social (Ministry of Public Health and Social Work) (2008) Indicadores Básicos de la Salud (Indicators of Basic Health). http:// www.mspas.gob.gt/menu/indicadores_basicos_de_salud/ indicadores.html (accessed January 2008).

22. Pan American Health Organization (2007) Central American Diabetes Initiative (CAMDI): Survey of Diabetes, Hypertension, and Chronic Disease Risk Factors. Villa Nueva, Guatemala 2006. Washington, DC: PAHO.

23. World Health Organization (2006) Global Database on Body Mass Index. http://www.who.int/bmi/index.jsp (accessed October 2007).

24. Martorell R, Habicht JP \& Rivera JA (1995) History and design of the INCAP longitudinal study (1969-77) and its follow-up (1988-89). J Nutr 125, Suppl., 1027S-1041S.

25. Grajeda R, Behrman JR, Flores R, Maluccio JA, Martorell R \& Stein AD (2005) The human capital study 2002-04: tracking, data collection, coverage, and attrition. Food Nutr Bull 26, Suppl. 1, S15-S24.

26. Conlisk AJ, Barnhart HX, Martorell R, Grajeda R \& Stein AD (2004) Maternal and child nutritional supplementation are inversely associated with fasting plasma glucose concentration in young Guatemalan adults. J Nutr 134, 890-897.

27. Rodriguez MM, Mendez H, Torun B, Schroeder D \& Stein $\mathrm{AD}$ (2002) Validation of a semi-quantitative food-frequency questionnaire for use among adults in Guatemala. Public Health Nutr 5, 691-699.

28. Menchu MT, Mendez H, Barrera MA \& Ortega L (1996) Nutritional Value of Central American Foods (in Spanish). Guatemala: Institute of Nutrition of Central America and Panama.

29. US Department of Agriculture Research Service (2008) USDA National Nutrient Database for Standard Reference. http://www.nal.usda.gov/fnic/foodcomp/search/ (accessed January 2008).

30. Ainsworth BE, Haskell WL, Whitt MC et al (2000) Compendium of physical activities: an update of activity codes and MET intensities. Med Sci Sports Exerc 32, Suppl., S498-S504

31. Gregory CO, Ramirez-Zea $M$, Martorell $R$ \& Stein $A D$ (2007) Activities contributing to energy expenditure among Guatemalan adults. Int J Behav Nutr Phys Act 4, 48.

32. Maluccio JA, Murphy A \& Yount KM (2005) Research note: a socioeconomic index for the INCAP longitudinal study 1969-77. Food Nutr Bull 26, Suppl. 1, S120-S124.

33. Ramirez-Zea M, Torun B, Martorell R \& Stein AD (2006) Anthropometric predictors of body fat as measured by hydrostatic weighing in Guatemalan adults. Am J Clin Nutr 83, 795-802.

34. World Health Organization Expert Committee (1995) Physical Status: The Use and Interpretation of Anthropometry. Geneva: WHO.

35. National Heart Lung and Blood Institute (2002) Third Report of the National Cholesterol Education Program (NCEP) Expert Panel on Detection, Evaluation, Treatment of High Blood Cholesterol in Adults (Adult Treatment Panel III). NIH Publication no. 02-5215. Bethesda, MD: National Heart Lung and Blood Institute, National Institutes of Health.

36. American Diabetes Association (2004) Diagnosis and classification of diabetes mellitus. Diabetes Care 27, Suppl. 1, S5-S10.

37. Grundy SM, Cleeman JI, Daniels SR et al (2005) Diagnosis and management of the metabolic syndrome: an American Heart Association/National Heart, Lung, and Blood Institute Scientific Statement. Circulation 112, $2735-2752$.

38. National Heart Lung and Blood Institute (2004) The Seventh Report of the Joint National Committee on Prevention, Detection, Evaluation, and Treatment of High Blood Pressure. NIH Publication no. 04-5230. Bethesda, MD: National Institutes of Health.

39. Kim SA, Stein AD \& Martorell R (2007) Country development and the association between parity and overweight. Int J Obes (Lond) 31, 805-812.

40. Little R \& Rubin D (2002) Statistical Analysis with Missing Data, 2nd ed. New Jersey: Wiley \& Son, Inc.

41. Rubin D (1987) Multiple Imputation for Nonresponse in Surveys. New York: Wiley.

42. FAO/WHO/UNU Expert Consultation (2004) Human Energy Requirements. Rome: WHO.

43. Ball K, Crawford D, Ireland P \& Hodge A (2003) Patterns and demographic predictors of 5-year weight change in a multi-ethnic cohort of men and women in Australia. Public Health Nutr 6, 269-281.

44. Lahmann PH, Lissner L, Gullberg B \& Berglund G (2000) Sociodemographic factors associated with long-term weight gain, current body fatness and central adiposity in Swedish women. Int $J$ Obes Relat Metab Disord 24, 685-694.

45. Hill JO, Wyatt HR, Reed GW \& Peters JC (2003) Obesity and the environment: where do we go from here? Science $\mathbf{2 9 9}$, 853-855.

46. Wang Y \& Beydoun MA (2007) The obesity epidemic in the United States - gender, age, socioeconomic, racial/ethnic, and geographic characteristics: a systematic review and meta-regression analysis. Epidemiol Rev 29, 6-28.

47. Popkin BM \& Doak CM (1998) The obesity epidemic is a worldwide phenomenon. Nutr Rev 56, Part 1, 106-114.

48. Rainwater DL, Mitchell BD, Comuzzie AG, VandeBerg JL, Stern MP \& MacCluer JW (2000) Association among 5-year changes in weight, physical activity, and cardiovascular 
disease risk factors in Mexican Americans. Am J Epidemiol 152, 974-982.

49. Srinivasan SR, Myers L \& Berenson GS (2001) Rate of change in adiposity and its relationship to concomitant changes in cardiovascular risk variables among biracial (black-white) children and young adults: The Bogalusa Heart Study. Metabolism 50, 299-305.

50. Ford ES, Williamson DF \& Liu S (1997) Weight change and diabetes incidence: findings from a national cohort of US adults. Am J Epidemiol 146, 214-222.

51. Folsom AR, Jacobs Jr DR, Wagenknecht LE et al. (1996) Increase in fasting insulin and glucose over seven years with increasing weight and inactivity of young adults. The CARDIA Study. Coronary Artery Risk Development in Young Adults. Am J Epidemiol 144, 235-246.
52. Friel S, Chopra M \& Satcher D (2007) Unequal weight: equity oriented policy responses to the global obesity epidemic. BMJ 335, 1241-1243.

53. Gomez LF, Mateus JC \& Cabrera G (2004) Leisure-time physical activity among women in a neighbourhood in Bogota, Colombia: prevalence and socio-demographic correlates. Cad Saude Publica 20, 1103-1109.

54. Matsudo SM, Matsudo VR, Araujo TL et al. (2003) The Agita Sao Paulo Program as a model for using physical activity to promote health. Rev Panam Salud Publ (Pan Am J Publ Health) 14, 265-272.

55. Uusitalo U, Feskens EJ, Tuomilehto J et al. (1996) Fall in total cholesterol concentration over five years in association with changes in fatty acid composition of cooking oil in Mauritius: cross sectional survey. BMJ 313, 1044-1046. 